\title{
Correlation of Salivary Thiocyanate levels and Oral Cytological Changes in Smokers
}

\author{
Radha Baral,' Bidhata Ojha, ${ }^{2}$ Dipshikha Bajracharya, ${ }^{2}$ Ganesh Silwal ${ }^{3}$ \\ 'Department of Oral Pathology, Dental Teaching Hospital, Institute of Medicine, Maharajgunj, Kathmandu, Nepal, \\ ${ }^{2}$ Department of Oral Pathology, Kantipur Dental College, Kathmandu, Nepal, ${ }^{3}$ Medical Officer, Nuwakot Sanjivani \\ Hospital, Nuwakot, Nepal
}

\section{ABSTRACT}

\section{Introduction}

Smokers are found to have higher salivary thiocyanate $(\mathrm{SCN})$ concentration compared to nonsmokers. This elevated level of the SCN in the saliva of smokers may be responsible for oral cancer risk among smokers through the nitrosation process. The objective of the study is to estimate salivary thiocyanate levels in tobacco smokers and non-smokers and correlate the levels of thiocyanate with cytomorphological changes in the oral mucosa.

\section{Methods}

This is a comparative cross-sectional study conducted among 40 non-smokers and 40 smokers in the outpatient department of Kantipur Dental College. Salivary thiocyanate level was estimated from the saliva sample. Cytological atypia, cytomorphometric changes and, micronuclei frequency were estimated from smear from buccal mucosa.

\section{Results}

Mean salivary thiocyanate level in smokers $(3.16 \pm 1.61 \mathrm{Mm} / \mathrm{l})$ was higher compared to non-smokers $(0.95$ $\pm 0.54 \mathrm{Mm} / \mathrm{l}$ ) which was statistically significant $(\mathrm{p}<0.001)$. There were also more atypical changes in oral mucosal cells in smokers than that found in nonsmokers. The mean nuclear-cytoplasmic ratio was also higher in smokers compared to nonsmokers which was statistically significant $(\mathrm{p}<0.001)$. Similarly, the micronuclei frequency in smokers $(1.79 \pm 0.76)$ was also found higher compared to micronuclei frequency in non-smokers $(1.24 \pm 0.74)$ which was statistically significant $(p=0.002)$. However, the correlation between salivary thiocyanate levels and cytomorphometric changes was weak.

\section{Conclusions}

Estimation of salivary thiocyanate level and cytological changes are non-invasive, painless, and prove to be an efficient tool in screening a large population as well as in aiding motivation of individuals for withdrawal of tobacco smoking.

Keywords: saliva; thiocyanate; tobacco smoking.

\section{INTRODUCTION}

Oral cancer is one of the most prevalent cancers and is one of the 10 most common causes of death worldwide. ${ }^{1,2}$ The etiology of the oral squamous cell carcinoma is multifactorial but the use of tobacco continues to be a prevalent risk factor. ${ }^{2,3}$
Tobacco use is associated with several changes in the oral mucous membrane, ranging from innocent and reversible lesions such as smoker's palate to oral cancer. ${ }^{4}$ Human saliva has been increasingly investigated as an alternative to serum for several diagnostic purposes. The idea

Correspondance: Dr. Radha Baral, Department of Oral Pathology, Dental Teaching Hospital, Institute of Medicine, Maharajguni, Nepal, Nepal, Email: radhabarall22@gmail.com, Phone: +977-9851246830 
of screening saliva-based tests is advantageous from several points of view including its ease, economic benefit, non-invasiveness, and possibility of repeated sampling. ${ }^{5}$

Thiocyanate $(\mathrm{SCN})$ is a normal constituent of body fluids such as serum, saliva, urine, and tears. Diet and tobacco are its main sources in the human body. Salivary SCN concentration in normal nonsmokers ranges from 0.5 to 2 $\mathrm{mM}$ with an average of $1 \mathrm{mM}$. However, heavy smokers may have a salivary concentration range as high as $6 \mathrm{mM} .6,7$ This elevated level of $\mathrm{SCN}$ in the saliva of smokers may be responsible for excessive cancer risk of smokers through the nitrosation process. ${ }^{6}$ Hence the objective of the study is to estimate salivary thiocyanate levels in tobacco smokers and non-smokers and correlate the levels of thiocyanate with cytomorphological changes in the oral mucosa.

\section{METHODS}

The study is a comparative cross-sectional study conducted in the outpatient department of Kantipur Dental College, Basundhara, Kathmandu, Nepal from October 2015 to April 2017. Forty participants with the habit of smoking at least 5 sticks per day for more than 3 years were included in the study. Individuals with any other habits like alcohol, tobacco chewing, and individuals having any visible lesion were excluded from the study. Only male participants were selected for the study because hormonal influence happens to be the differentiating factor for the cytomorphometric trends of males and females. ${ }^{8}$ Forty controls without any habit, age, and sex-matched were selected to ensure the comparability. Ethical approval was obtained from Institutional Review Committee (IRC), Kantipur Dental College, and informed written consent was taken from every participant of the study. After getting informed consent about $5 \mathrm{ml}$ of whole unstimulated saliva was collected by spitting method in the afternoon time from every participant after rinsing the mouth with clean water. The salivary thiocyanate level was estimated by the method given by Hovinen J et al. ${ }^{9}$ Cytological atypia, cytomorphometric changes, and micronuclei frequency were estimated from smear from buccal mucosa stained with Papanicolaou stain (PAP).

Atypia was assessed cytologically by using the following criteria. The presence of two or more of the following features was considered consistent with atypia: nuclear enlargement associated with increase nuclear-cytoplasmic ratio, hyperchromatism, chromatin clumping with moderately prominent nucleoli, irregular nuclear membrane and bi or multinucleation, scant cytoplasm, and variation in size and/or shape of the cells and nuclei. The percentages were calculated by counting atypical cells in five microscopic fields using the 40X objective. Then the mean number of atypical cells was calculated and divided by the total number of cells to yield a percentage of atypical cells per field. If the atypical cells were $3-10 \%$, it was considered slight and given a score value as follows: for 3-6\% atypical cells, the score assigned was $(+)$ and for $7-10 \%$ the score was $(++)$. More than 10 atypical cells were consistent with marked atypia. The marked changes were scored as follows: $10-15 \%$ atypical cells which was correspondence to mild cytological atypia; $16-20 \%$, which was equivalence to moderate cytological atypia, and above $21 \%$, which was equivalence to severe cytological atypia. ${ }^{10}$

For quantitative cytomorphometric analysis, images were captured with the help of the microscope with an attached camera system (Labomed microscope, Labomed camera with pixel pro software). Photomicrographs were obtained at x400 magnification for individual unfolded cells with a clear outline. Twenty cells 
per slide were analyzed for the cytoplasmic area (CA), nuclear area (NA), and nuclearcytoplasmic ratio (NA/CA) ratio using Motic, Image Plus, version 2.0 software (Figure 1). ${ }^{11,12}$ Micronuclei $(\mathrm{MN})$ were identified according to the criteria given by Tolbert. ${ }^{13}$ Screening of slide was done in a zigzag manner starting from one end of the slide and approaching towards the other end. ${ }^{14}$ The average frequency of $\mathrm{MN}$ was further tabulated based on the following formula:

The average frequency of $\mathrm{MN}=$ Total number of $\mathrm{MN} /$ Total number of cells with MN. ${ }^{14}$

All data were tabulated in Microsoft Excel and analyzed in SPSS software version 16.

\section{RESULTS}

Among the group of smokers highest number of participants (35\%) smoked 5 or fewer cigarettes per day. The least number of participants (15\%) smoked 16 or more cigarettes per day (Figure 2). Most of the participants (42.5\%) had smoked for 5-10 years and the least number of participants $(10 \%)$ had smoked for more than 20 years (Figure 3).

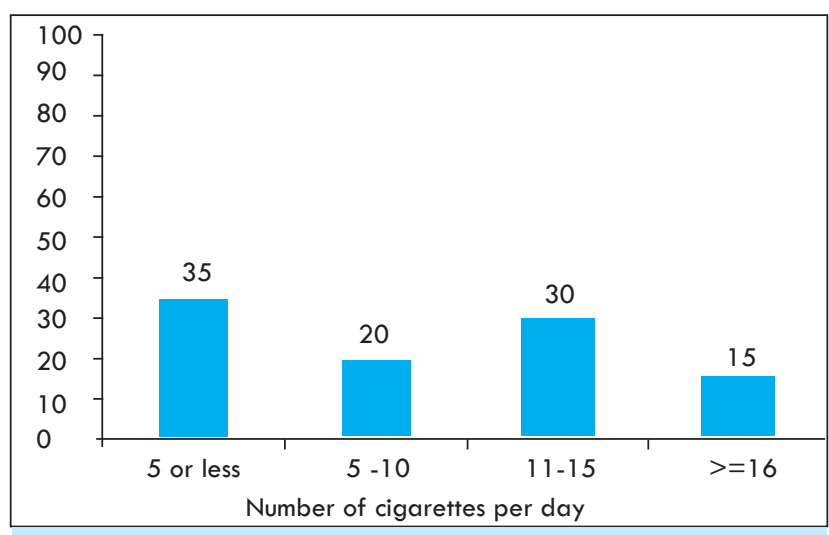

Figure 2. Number of cigarettes per day $(n=40)$

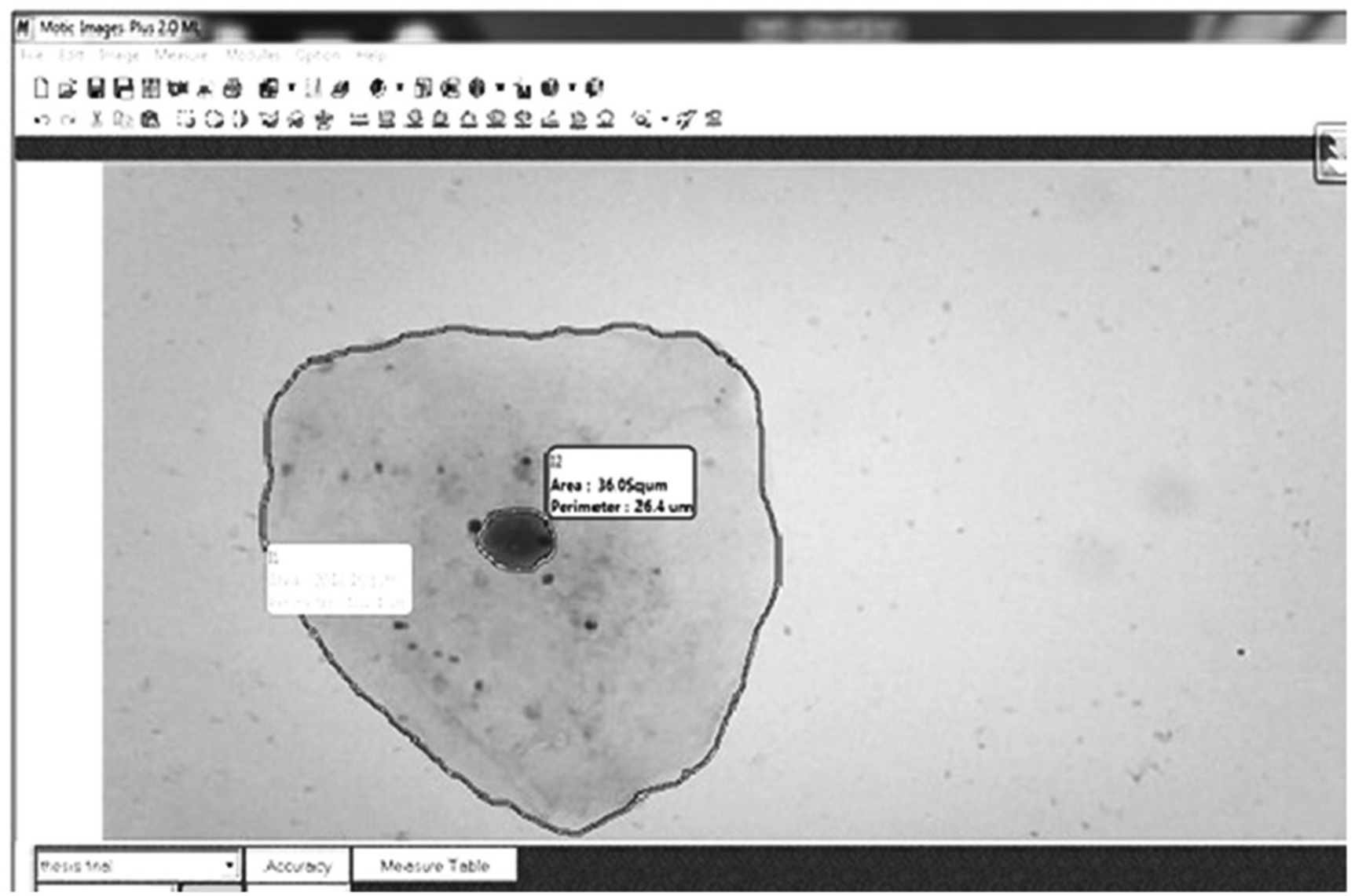

Figure 1. Measurement of the nuclear area and cytoplasmic area of a cell in Motic image plus version 2 image analysis software. 


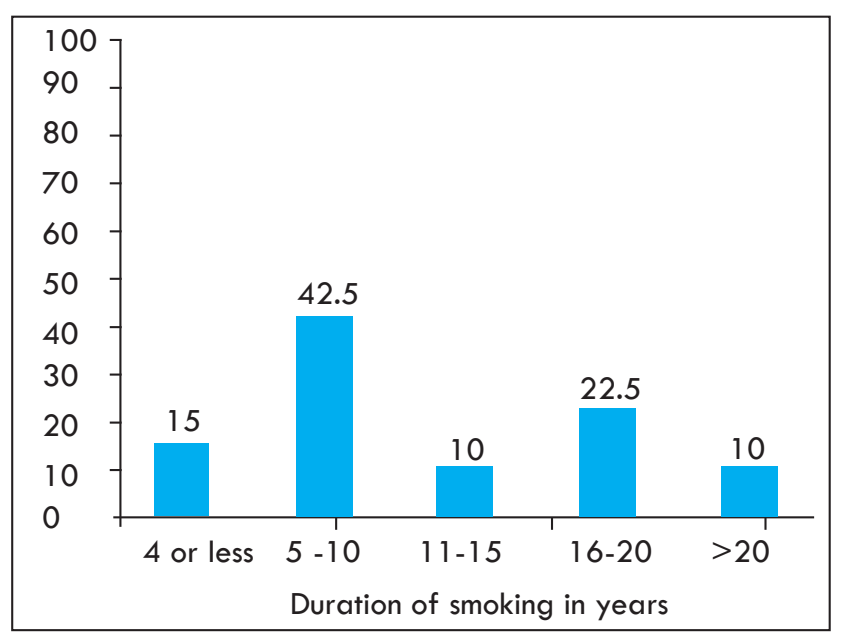

Figure 3. Duration of smoking $(n=40)$

Among the non-smokers, 75\% revealed less than $3 \%$ atypical cells per field (which is equivalent to no atypia) while the rest $25 \%$ of the participants revealed 3 to $6 \%$ atypical cell per field (slight atypia). While among non-smokers participants, 95\% participants revealed less than 3\% atypical cells per field (which is equivalent to no atypia), and 3 to $6 \%$ atypical cells per field (slight atypia) was observed in only $5 \%$ of the participant which is less than the value observed in participants with the smoking habit (Figure 4).

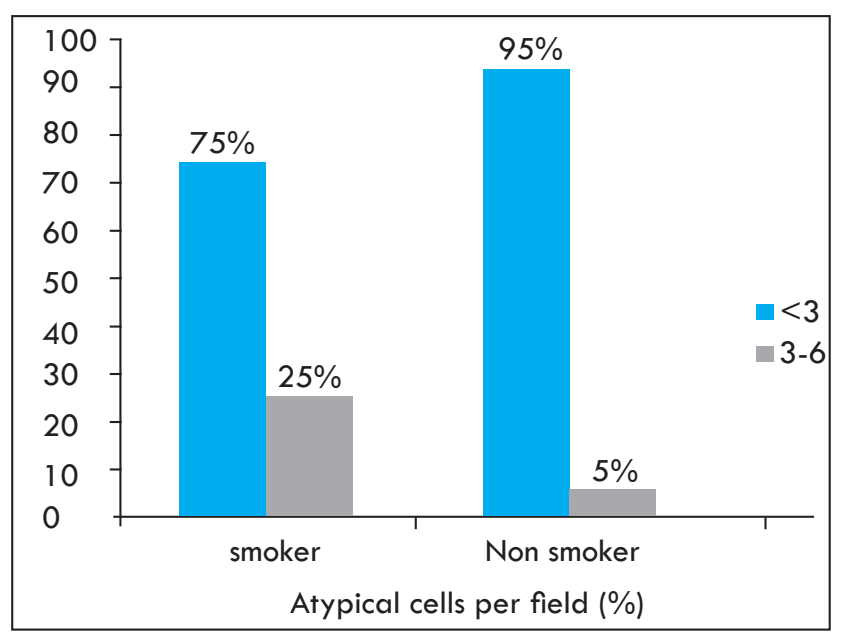

Figure 4. Comparison of atypical cell per field between smokers and non-smokers

Mean salivary thiocyanate level smokers (3.16 $\pm 1.61 \mathrm{Mm} / \mathrm{l})$ was higher compared to non-smokers $(0.95 \pm 0.54 \mathrm{Mm} / \mathrm{l})$ which was statistically significant $(\mathrm{p}<0.001)$ (Table 1). Comparisons of mean cytoplasmic area, nuclear area, and nuclear-cytoplasmic ratio were done with the help of the independent sample t-test. The mean cytoplasmic area was smaller among smokers compared to nonsmokers which were statistically significant $(p<0.001)$. This highlights the fact that smoking is associated with a decrease in the cytoplasmic area. The mean nuclear area was greater among smokers however, the difference in mean was not statistically significant $(p=0.137)$. For the nuclear-cytoplasmic ratio, the mean difference was significant for smokers and non-smokers $(p<0.001)$ with the higher nuclear-cytoplasmic ratio in smokers (Table 1 ).

Table 1. Comparison of salivary thiocyanate level, mean cytoplasmic area, nuclear area, nuclear-cytoplasmic ratio, and micronuclei frequency between smokers and nonsmokers

*Statistically significant

\begin{tabular}{|l|l|c|c|c|c|c|}
\hline \multirow{2}{*}{$\begin{array}{c}\text { Cytomorphometric } \\
\text { parameters }\end{array}$} & \multicolumn{2}{|c|}{ Smokers } & \multicolumn{2}{|c|}{ Nonsmokers } & $\begin{array}{r}\text { t-test } \\
\text { value }\end{array}$ & $\begin{array}{c}P \\
\text { value }\end{array}$ \\
\cline { 2 - 6 } & Mean & \multicolumn{1}{|c|}{ SD } & Mean & SD & \\
\hline $\begin{array}{l}\text { Thiocyanate level } \\
(\text { Mm/L) }\end{array}$ & 3.16 & 1.61 & 0.95 & 0.54 & 8.222 & $<0.001^{*}$ \\
\hline $\begin{array}{l}\text { Cytoplasmic area } \\
\left(\mu \mathrm{m}^{2}\right)\end{array}$ & 2920.60 & 443.58 & 3380.70 & 629.40 & -3.763 & $<0.001^{*}$ \\
\hline Nuclear area $\left(\mu \mathrm{m}^{2}\right)$ & 64.05 & 9.09 & 61.08 & 8.41 & 1.503 & 0.137 \\
\hline $\begin{array}{l}\text { Nuclear } \\
\text { cytoplasmic ratio }\end{array}$ & 0.02 & 0.00 & 0.02 & 0.00 & 4.254 & $<0.001^{*}$ \\
\hline MN frequency & 1.79 & 0.76 & 1.24 & 0.74 & 3.258 & $0.002^{*}$ \\
\hline
\end{tabular}

Similarly, the micronuclei frequency in smokers (1.79 \pm 0.76$)$ was also found higher compared to micronuclei frequency in non-smokers (1.24 \pm 0.74) which was statistically significant $(\mathrm{p}=0.002)$. Thus, showing that an increase in $\mathrm{MN}$ frequency is associated with smoking (Table 1) (Figure 5). 


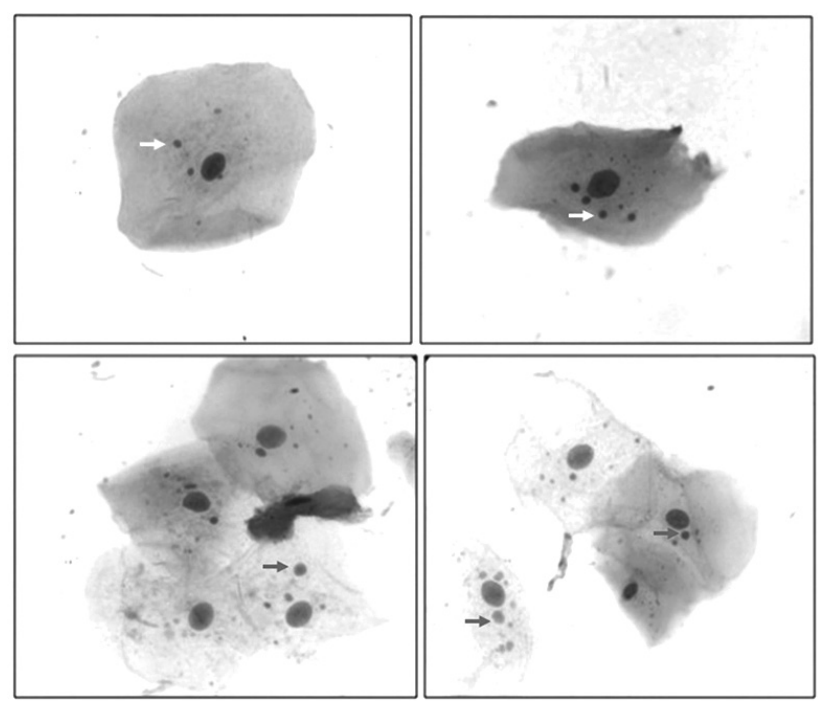

Figure 5. Photomicrographs showing micronuclei (indicated by arrow) in buccal mucosal cells of smoker in Papanicolaou stain (1000X)

Correlations of salivary thiocyanate level with the cytoplasmic area, nuclear area, and nuclearcytoplasmic ratio was done with the help of Pearson correlation analysis which revealed the correlation coefficient of salivary thiocyanate level with the cytoplasmic area, nuclear area, nuclear-cytoplasmic ratio, atypical cells per field, and micronuclei frequency among smokers was fairly weak which did not indicate linear relationship (Table 2).

Table 2. Correlation of Salivary thiocyanate with the mean cytoplasmic area, mean nuclear area nuclear-cytoplasmic ratio, atypical cell per field, and micronuclei frequency among smokers.

\begin{tabular}{|l|l|l|l|l|l|}
\hline & $\begin{array}{c}\text { Cytoplasmic } \\
\text { area }\end{array}$ & $\begin{array}{c}\text { Nuclear } \\
\text { area }\end{array}$ & $\begin{array}{c}\text { Nuclear } \\
\text { cytoplasmic } \\
\text { ratio }\end{array}$ & $\begin{array}{c}\text { Atypical } \\
\text { cells per } \\
\text { field }\end{array}$ & $\begin{array}{c}\text { MN } \\
\text { frequency }\end{array}$ \\
\hline $\begin{array}{l}\text { Pearson } \\
\text { correlation }\end{array}$ & 0.04 & 0.015 & 0.009 & 0.213 & 0.062 \\
\hline$p$ & 0.804 & 0.928 & 0.954 & 0.187 & 0.703 \\
\hline
\end{tabular}

\section{DISCUSSION}

Tobacco smoking is a widespread habit practiced by people from most cultures and societies all around the globe. Tobacco has a direct carcinogenic effect on oral epithelial cells of the oral mucous membrane. There are more than 300 carcinogens in the smoke of tobacco. ${ }^{4}$ Thiocyanate is produced in the body from metabolic conversion of the hydrogen cyanide which is obtained from the inhalation of tobacco smoke. Thiocyanate in blood, urine, and saliva is consistently related to cigarette smoking in laboratory field studies. Thiocyanate has a property to induce cancerous changes in the epithelium as it is secreted in saliva and has a long half-life being constantly in contact with mucosa. ${ }^{6,15}$

In the present study, the mean salivary thiocyanate level among smokers (3.16 \pm 1.61 $\mathrm{Mm} / \mathrm{l}$ ) was observed higher compared to mean salivary thiocyanate level among non-smoker $(0.95 \pm 0.54 \mathrm{Mm} / \mathrm{l})$ (Table 1$)$. Consistent with the current study, previous studies have revealed that salivary SCN concentration in normal nonsmokers ranges from 0.5 to $2 \mathrm{mM}$ with an average of $1 \mathrm{mM}$. These studies have also mentioned that the salivary thiocyanate concentration in heavy smokers ranges as high as $6 \mathrm{mM} .^{6}$ Tsuge $\mathrm{K}$ et al did a study on salivary and plasma thiocyanate level and found that the quantification of plasma thiocyanate and salivary thiocyanate provide a reliable predictor of cyanide exposure such as tobacco smoking. ${ }^{16}$ In another study Patil PB and Patil BR found a significant relationship between the relative amount of tobacco smoke and the amount of thiocyanate present in the saliva. ${ }^{5}$

In a study performed by Ahmed $\mathrm{H}$ et al of assessment of cytological atypia in smokers, alcoholics, and hot meal users, among the individuals with smoking habit cytological atypia with increased keratinization was observed in $45 \% .^{10}$ Similar to these findings Abdelaziz M et al also found $12 \%$ cytological atypia among smokers with increased keratinization in $14 \%$ of the individual. ${ }^{17}$ In another study Jaber A et al also found a significant relationship between Papanicolaou classes and cigarette smoking duration and frequency. ${ }^{18}$ These findings are 
consistent with the present study.

Previous studies including the present study signify that whatever may be the criteria and methods used for the determination of atypical changes, certain dysplastic changes are occurring in the oral mucosa of the smoking individuals compared to non-smokers even without visible lesion.

A study in which nuclear and cytoplasmic areas were determined by image analysis software to have shown a decrease in cytoplasmic area and an increase in nuclear area in smokers compared to non-smoking controls. These findings are consistent with the result of the present study (Table 1). ${ }^{2}$ Similar finding was observed in another study of evaluation of cytological alteration or oral mucosa in smokers and waterpipe users. ${ }^{12}$

In another cytomorphometric study of buccal mucosal cells, Shetty $R$ et al also found a decrease in mean cytoplasmic area and an increase in mean nuclear area in smokers compared to non-smokers so there was an overall increase in nuclear-cytoplasmic ratio. This study also highlighted the dose-dependent cytomorphometric alteration in smokers. ${ }^{19}$ Hedge $\mathrm{V}$ et al also suggested that the decrease in the mean cytoplasmic diameter of exfoliated mucosal cells could serve as an early indicator of dysplastic changes in which lesions appear histologically benign which was also found in the present study. ${ }^{20}$

In the current study, although statistically not significant, an increase in nuclear size in smokers compared to the control group was observed. It seems that an increase in nuclear size is a kind of cellular adaptation in response to the oral mucosal epithelium to the irritation. In other words, it results from the increase of nuclear DNA content. Creating a cell irritation, by smoking facilitate the aging process of oral mucosal cells. ${ }^{12}$ Epithelial cells of the oral mucosa have a decreased turnover, so cells remain in the cell cycle for longer periods resulting in a delayed cell division. As a result, proteins that are synthesized within the nucleus divide slowly, which in turn, it increases the nuclear size. Morphological changes occurring in these mucosal cells are might be due to various tobacco byproducts. ${ }^{12}$ Decrease in the cytoplasmic area and an increase in the nuclear area and nuclear cytoplasmic ratio in cells isolated from the buccal mucosa of tobacco users demonstrated by present study could be used as early indicators of dysplastic changes in the oral mucosa.

The micronuclei frequency in smokers (1.79 $\pm 0.76)$ was also found higher compared to micronuclei frequency in non-smokers (1.24 \pm 0.74 ) which was statistically significant ( $p=0.002)$. Thus, showing that an increase in MN frequency is associated with smoking (Table 1), (Figure 5). In a similar study done to evaluate the mean number of $\mathrm{MN}$ in smokeless tobacco users, smokers, and healthy control, the mean number of MN was found higher in smokers compared to non-smokers. This study also concluded that the increase in the number of $\mathrm{MN}$ provides evidence that tobacco users of any form may be at high risk for developing oral cancer compared to non-tobacco users. ${ }^{21}$

The present study showed a fairly weak correlation of salivary thiocyanate level with the cytoplasmic area, nuclear area, nuclearcytoplasmic ratio, atypical cells per field, and micronuclei frequency among smokers (Table 2 ). There are very few studies on literature correlating salivary thiocyanate levels with cytological alteration to compare with the finding of the current study. On extensive literature review only one study was found correlating thiocyanate level with micronuclei frequency which was performed by Baldawa PS et al in this study they evaluated the levels of salivary thiocyanate and occurrence of $\mathrm{MN}$ in 
smokers and nonsmokers and found a positive association between salivary thiocyanate and occurrence of $\mathrm{MN}$ contrasting the findings of present study.22

This study indicates higher salivary thiocyanate levels signify greater exposure to tobacco smoke. The present study shows that cytomorphological changes appear in the healthy-looking oral mucosa even before the appearance of visible lesions in smokers. Hence, identification of cytomorphological changes in high-risk groups like smokers before the appearance of obvious lesion helps in early diagnosis, better treatment results, and a decrease in morbidity and mortality from oral cancer. Moreover, demonstration of these changes can be used in patient motivation for tobacco cessation. However, further studies with a larger sample size are mandatory in the future to determine the value of salivary thiocyanate level as a marker in the early diagnosis of malignant changes.

\section{CONCLUSIONS}

Estimation of salivary thiocyanate levels are noninvasive, painless, and prove to be an efficient tool in screening a large population as well as in aiding motivation of individuals for withdrawal of tobacco smoking.

\section{Conflict of Interest: None}

\section{ACKNOWLEDGEMENTS}

We would like to acknowledge Prof. Dr. S. Bhattacharyya, Dr. Nirjala Laxmi Madhikarmi for their guidance and support.

\section{REFERENCES}

1. Garg D, Sunil MK, Singh PP, Singla N, Rani SA, Kaur B. Serum lipid profile in oral precancer and cancer: a diagnostic or prognostic marker? J Int Oral Heal. 2014;6(2):33-9.

2. Aghababaie $\mathrm{M}$, Tahmasbi arashlow M, Tahmasbi Arashlow F, Nassab SA. Exfoliative Cytology of Oral Mucosa among Smokers, Opium Addicts and Non-smokers: A Cytomorphometric Study. Arch Iran Med. 2013;16(12):72530.

3. Udayashankar U, Guduru VS, Ananthaneni A, Ramisetty SD, Kuberappa PH, Namala S. Evaluation of cytomorphometric changes in tobacco users and diagnosed oral squamous cell carcinoma individuals. J Cytol. 2016;33(3):125-9.

4. Johnson N, Bain C, Group E.

Tobacco and oral disease. Br Dent J. 2000;189(4):200-6.

5. Patil PB, Patil BR. Saliva : A diagnostic biomarker of periodontal diseases. J Indian Soc Periodontol. 2011;15(4):6-12.

6. Kalburgi CV, Naik K, Kokatnur M, Warad S. Estimation and correlation of salivary thiocyanate levels in healthy and different forms of tobacco users having chronic periodontitis: A crosssectional biochemical study. Contemp Clin Dent. 2014;5(2):182-6.

7. Rai B, Kharb S, Anand SC. Salivary enzymes and thiocyanate: Salivary markers of periodontitis among smokers and non-smokers; a pilot study. Adv Med Dent Sci. 2007;1:1-4.

8. Patel P, Kumar S, Kumar V, Vidya GD. Quantitative cytomorphometric analysis of exfoliated normal gingival cells. Journal Cytol. 2011;28(2):66-72. 
9. Hovinen J, Lahti M, Vilpo J. Spectrophotometric Determination of Thiocyanate in Human Saliva. J Chem Educ. 1999;76(9):1281-2.

10. Ahmed HG, Ebnoof SO, Hussen MO, Gbreel AY. Oral Epithelial Atypical Changes in Apparently Healthy Oral Mucosa Exposed to Smoking, Alcohol, Peppers and Hot Meals, Using the AgNOR and Papanicolaou Staining Techniques. Diagn Cytopathol. 2009;38(7):489-95.

11. Khot K.A cytomorphometric analysis of oral mucosal changes in tobacco users. J Nat Sci Biol Med. 2015;6(1):2015-7.

12. Seifi S, Feizi F, Mehdizadeh M, Khafri $\mathrm{S}$, Ahmadi B. Evaluation of Cytological Alterations of Oral Mucosa in Smokers and Waterpipe Users. Cell J. 2013;15(4):302-9.

13. Shashikala $\mathrm{R}$, Indira AP, Manjunath GS. Role of micronucleus in oral exfoliative cytology. J Pharm Bioallied Sci. 2015;7(2):409.

14. Jadhav K, Gupta N, Mujib BA. Micronuclei : An essential biomarker in oral exfoliated cells for grading of oral squamous cell carcinoma. J Cytol. 2011;28(1):7-12.

15. Pullishery F, Panchmal GS, Siddique S. Salivary Thiocyanate, Uric Acid, and $\mathrm{pH}$ as Biomarkers of Periodontal Disease in Tobacco Users and NonUsers An In Vitro Study. J Clin Diagnostic Res. 2015;9(7):47-50.

16. Tsuge K, Kataoka M, Seto Y. Cyanide and Thiocyanate Levels in Blood and Saliva of Healthy Adult Volunteers. J Heal Sci. 2000;46(5):343-50.

17. Abdelaziz MS, Osman TE. Detection of Cytomorphological Changes in Oral Mucosa among Alcoholics and Cigarette Smokers. Oman Med J. 2011;26(5):349-52.

18. Al Bahrani AJ. Evaluation of the cytological changes of oral mucosal cells in Smokers by using Exfoliative Pap Stain. Mustansiria Dent J. 2013;10(1):124-9.

19. Shetty R, Mukherjee S, Dutta N, Bhagat K, Sushma KN, Pandey V. Cytomorphometric analysis of oral squames Tobacco Smokers using oral brush biopsy: An exfoliative cytological study. Int Arch Integr Med. 2016;3(5):14-9.

20. Hegde V. Cytomorphometric analysis of squames from oral premalignant and malignant lesions. J Clin Exp Dent. 2011;3(5):441-4.

21. Bansal H, Sandhu VS, Bhandari R, Sharma D. Evaluation of micronuclei in tobacco users: A study in Punjabi population. Contemp Clin Dent. 2012;3(2):184.

22. Baldawa PS, Kulkarni V V, Koshy A V, Shaikh SS, Varu R. Levels of salivary thiocyanate and its relation with occurrence of micronuclei using exfoliative cytology in smokers and nonsmokers. Indian J Dent Res. 2017;26(7):568-73.

Citation: Baral R, Ojha B, Bajracharya D, Silwal G. Correlation of Salivary Thiocyanate levels and Oral Cytological Changes in Smokers. JCMS Nepal. 2020; 16(4):259-266. 